Original Article

\title{
Prevalence of Dental Caries, its Associated Risk Factors and Treatment Needs among School Aged Children at Kimironko II Primary School, Kigali, Rwanda
}

Donat Uwayezu $^{1 *}$, Peace Uwambaye ${ }^{1}$, Anne Marie Uwitonze ${ }^{1}$, Julienne Murererehe ${ }^{1}$, Emmanuel Nzabonimana ${ }^{1}$, Marie Claire Ineza ${ }^{1}$, Eliane Ingabire Harelimana ${ }^{1}$, Usiel Nsabimana $^{1}$, Deeva Singh ${ }^{1}$, Emma Nizeyimana $^{1}$, Eugene Nshimiyimana $^{1}$, Joselyne Muhawenimana ${ }^{1}$, Rene Tuyibuke ${ }^{1}$, Eustache Ntigura ${ }^{1}$, Agnes Gatarayiha ${ }^{1}$

${ }^{1}$ Department of Preventive and Community Dentistry, School of Dentistry, College of Medicine and Health Sciences, University of Rwanda, Rwanda.

*Corresponding author: Donat Uwayezu. Department of Preventive and Community Dentistry, School of Dentistry, College of Medicine and Health Sciences, University of Rwanda, Remera Campus, KG 11 Ave, 47, Kigali, Rwanda. Email: uwadonatus@gmail.com

\begin{abstract}
Background

Dental caries is still a health problem worldwide, its prevalence and incidence are associated with various factors like age, sex, social status, dietary patterns and oral hygiene habits.

Methodology

A Secondary data collected from outreaches done by UR CMHS, School of Dentistry at Kimironko II Primary School was analyzed. This secondary data had been obtained using structured questionnaires with close ended questions. Clinical examination had also been done to gather information. SPSS statistical software package version 22 was used to analyse data from Community outreach done at Kimironko Primary School in August 2019.
\end{abstract}

\section{Results}

The prevalence of dental caries of $42.4 \%$ was found among children aged 6-12 years old of Kimironko II Primary School. The researchers found the following to be statistically significantly associated with prevalence of dental caries: gender $(p=0.042)$, dental visits $(p=0.001)$, and use of chew sticks or miswaks $(p=0.041)$. Females were 1.4 times more likely to develop dental caries (OR: $1.462 ; 95 \% \mathrm{CI}: 1.16-2.017 ; \mathrm{p}=0.021$ ) and children who did not use toothpick were 2 times more likely to develop dental caries (OR: 2.149; 95\%CI: 1.251-4.395; $\mathrm{p}=0.036)$, whereas visiting a dental practitioner was protective against dental caries (OR: 0.362, 95\% CI: 0.251-0.516; $\mathrm{p}=0.001$ ).

\section{Conclusion}

Dental caries is prevalent among children of Kimironko II Primary School. Appropriate preventive measures should be taken to protect those found to be exposed.

Rwanda J Med Health Sci 2021;4(3):341-346

Keywords: Dental caries, risk factors, treatment needs, School-aged children, Rwanda

\section{Introduction}

Dental caries is a significant community oral health problem Worldwide and it is among the most widespread non-communicable diseases.[1] In 2015, Global burden of disease report presented that dental caries was a prevalent condition from which 560 million children suffered.[2] Moreover, World Health Organization (WHO) report showed that 60 to $90 \%$ of school children have experienced dental caries condition. [3] Therefore, this dental problem needs global attention to preserve the good oral health of children.
In developed countries, dental caries have been found to be high in school children. This higher prevalence is reported to be associated with high intake of processed sugary foods and drinks such as biscuits, cake, chocolates, sweets, juice and soda. For example, in USA, the study done by Fleming et al in 2018 showed a high prevalence $(50.5 \%)$ of dental caries among 6-11 years old children during the National Health and Nutrition Survey.[4] In the North-East of Jordan, dental caries prevalence was $78.7 \%$ among 6-12 years children and dietary habits played an important role in dental caries development.[5] 
In Africa, dental caries problem also exists among school children where for example in the study done in Nigeria on 358 school children aged 12 to 15 years randomly selected from different school presented a high prevalence of dental caries (98.6\%).[6] The studies done in East African countries, reported the high magnitude of the problem in Tanzania and Uganda among schoolchildren where the overall prevalence of dental caries in those two countries was 61\%.[7] In the majority of all these different countries, consumption of sugary food and drinks, oral hygiene behaviors, dietary habits, gender, ages and residence were presented as the associated risk factors.[8-10] On the other hand, the use of fluoride, diet counseling and oral health education on oral hygiene were reported as preventive measures where even in some cases restorative treatment and extraction were required to help those who are in danger. $[11,12]$

In Rwanda, it has been reported that dental caries and gum diseases are the most predominant ill health conditions in outpatient visits. A study conducted by Mukashyaka et al in 2015 reported that almost all dental patients, at Butaro Cancer Center of Excellence (BCCE)/Butaro District Hospital (BDH), were suffering from dental caries. [13] However, even though the main complaints of dental patients in hospitals are dental caries, there is a little knowledge on prevalence of dental caries and associated risk factors among school children. During the oral health community outreach at Kimironko II Primary School, it was found that dental caries affected the quality of oral health of school children by causing them pain, discomfort, infections and absenteeism to school; This study, therefore was undertaken to determine the prevalence, associated risk factors and treatment needs. The study findings can be used for advocacy and instituting of appropriate policies to improve oral health status among school children and to design the suitable educational, preventive and treatment measures.

\section{Methods}

A secondary analysis of UR-CMHS School of Dentistry outreach data from Kimironko II Primary School was done. The study participants were all the children both males and females that were screened and filled the questionnaire of community outreach and whose data was complete. This questionnaire comprised of different parts including demographic information, dietary habits, oral hygiene practices, and another part on which screening data was recorded. During the analysis, data was coded and entered in computer using SPPS version 22 .
Firstly, descriptive statistic using frequency and percentage was done and then analytical statistics were done using Chi-Square test to assess the association between demographic factors, dietary factors and oral health behavior factors with dental caries in bivariate analysis. In addition, multivariable analysis was performed to identify the factors that were independently associated with dental caries. The significance level was set at $p<0.05$. The variables that were analyzed during the research study were age, gender, frequency of sugary drinks consumption, frequency of brushing, use of tooth paste and toothbrush, dental floss, chew stick/miswak, the act of visiting a dental practitioner and treatment need. The dependent variable was dental caries categorized as present or absent.

\section{Results}

\section{Demographic characteristic of participants}

Out of 670 screened children, those who filled the questionnaire and fit the inclusion criteria were 660 children equal to $96 \%$ of all children studied at Kimironko II Primary School during the period of oral health community outreach. Among them, majority were male 342 (51.8\%) compared to female who were 318 (48.2\%). The majority of the participants were in age group of $7-12$ years at $528(80.0 \%)$, while the least, 36 $(5.5 \%)$, were aged 6 years and below, children aged 13 years and above were $96(14.5 \%)$ as summarized in Table1.

\section{Table 1. Demographic characteristic of study participants $(n=660)$}

\begin{tabular}{lcc}
\hline Variables & Number (660) & \% \\
\hline Age (years) & & \\
$\leq 6$ years old & 36 & 5.5 \\
7 to 12 years old & 528 & 80 \\
$\geq 13 y e a r s$ old & 96 & 14.5 \\
Total & $\mathbf{6 6 0}$ & $\mathbf{1 0 0}$ \\
Gender & & \\
Male & 342 & 51.8 \\
Female & 318 & 48.2 \\
Total & $\mathbf{6 6 0}$ & $\mathbf{1 0 0}$ \\
\hline
\end{tabular}


Prevalence of Dental caries according to sociodemographic characteristics and dietary habits of the pupils

Out of 660 participants, 280 (42.42\%) had dental caries. Based on the gender of participants, prevalence of dental caries was found to be higher in males (46.19\%) compared to females $(38.36 \%)$. The highest prevalence of dental caries was found in the age group $\leq 6$ years at $(44.4 \%)$ whereas the lowest prevalence $(37.5 \%)$ was among the 13 years and above age group. With regard to taking sugary drinks, those who took them once or more times per day $(44.02 \%)$ had a higher prevalence of dental caries than the ones who did so a few times per week or never (38.94\%). Those who had not visited the dental practitioner had a higher prevalence $(60.22 \%)$ compared to those who visited a dental practitioner (35.95\%). The result also showed that, children who brushed twice or several times per day had a lower prevalence $(37.60 \%)$, compared to those who never did so or brushed once a day (45.07\%). Furthermore, a higher prevalence of dental caries was found in children who did not use dental floss at $43.26 \%$,toothpicks (43.66\%), and toothbrush with toothpaste $(53.22 \%)$ compared to those who used dental floss (24.13\%), toothbrush with toothpaste at (41.30) (Table 2)

Table 2. Prevalence of dental caries among the study among School Aged Children at Kimironko II Primary School

\begin{tabular}{|c|c|c|c|}
\hline \multirow[t]{2}{*}{ Variable } & \multicolumn{2}{|c|}{ Dental Caries } & \multirow[b]{2}{*}{ P value } \\
\hline & Yes $\mathbf{n}(\%)$ & No $n(\%)$ & \\
\hline Age (years) & & & 0.566 \\
\hline$\leq 6$ years old & $16(44.44)$ & $20(55.55)$ & \\
\hline 7 to 12 years old & $228(43.18)$ & $300(56.82)$ & \\
\hline$\geq 13$ years old & $36(37.5)$ & $36(37.5)$ & \\
\hline Gender & & & 0.042 \\
\hline Male & $158(46.19)$ & $184(53.80)$ & \\
\hline Female & $122(38.36)$ & $196(61.63)$ & \\
\hline $\begin{array}{l}\text { Frequency of sugary drinks } \\
\text { consumption }\end{array}$ & & & 0.355 \\
\hline Once or more times per day & $199(44.02)$ & $253(55.97)$ & \\
\hline $\begin{array}{l}\text { A few times per weeks or } \\
\text { never }\end{array}$ & $81(38.94)$ & $127(61.05)$ & \\
\hline $\begin{array}{l}\text { Visiting a dental practi- } \\
\text { tioner }\end{array}$ & & & 0.001 \\
\hline Yes & $174(35.95)$ & $310(64.04)$ & \\
\hline No & $106(60.22)$ & 70 (39.77) & \\
\hline Frequency of brushing & & & 0.129 \\
\hline $\begin{array}{l}\text { Twice or several times per a } \\
\text { day }\end{array}$ & $88(37.60)$ & $146(62.39)$ & \\
\hline $\begin{array}{l}\text { Once a day, week, month or } \\
\text { never }\end{array}$ & 192 (45.07) & $234(54.92)$ & \\
\hline Use of dental floss & & & 0.056 \\
\hline Yes & 7 (24.13) & $22(75.86)$ & \\
\hline No & 273 (43.26) & 358 (56.73) & \\
\hline Use of toothpicks & & & 0.041 \\
\hline Yes & $11(25.00)$ & $33(75.00)$ & \\
\hline No & $269(43.66)$ & $347(56.33)$ & \\
\hline $\begin{array}{l}\text { Use of and toothbrush with } \\
\text { tooth paste }\end{array}$ & & & 0.353 \\
\hline Yes & $247(41.30)$ & $351(58.69)$ & \\
\hline No & $33(53.22)$ & $29(46.77)$ & \\
\hline Total Prevalence & $280(42.42)$ & $380(57.57)$ & \\
\hline
\end{tabular}


Factors associated with dental caries among School Aged Children at Kimironko II Primary School

Gender of participants $(\mathrm{p}=0.042)$, frequency of visiting the dental practitioner $(\mathrm{p}<0.000)$ and use of chew $\operatorname{stick}(p=0.041)$ were statistical significantly associated with dental caries among school aged children. However, age, frequency of sugar drinks consumption $(p=0.355)$, frequency of brushing ( $p=0.129)$, use of dental floss $(p=0.056)$, toothpaste and toothbrush $(p=0.353)$ respectively were not statistically significantly associated with dental caries among participants (Table 2). Multivariable analysis showed that among the three independent variables that kept the statistical association with the dependent variable in bivariate analysis, males were 1.4 times more likely to develop dental caries compared to females (OR:1.462;95\%CI:1.160-2.017; $\mathrm{p}=0.021)$ and children who did not use toothpicks were 2 times more likely to develop dental caries compared to those who used it (OR:2.149;95\%CI:1.251-4.395; $\quad \mathrm{p}=0.036)$ whereas those visiting a dental practitioner were less likely to develop dental caries compared to those who did not visit a dental partitioner (OR:0.362,95\%CI:.251-.516; $\mathrm{p}=0.001$ ). (Table 3)

Table 3. Multivariable analysis by logistic regression model to determine factors independently associated with dental caries among the pupils

\begin{tabular}{lrrr}
\hline Variable & OR & 95\%CI & P-Value \\
\hline $\begin{array}{l}\text { Gender } \\
\text { Female }\end{array}$ & 1 & & \\
$\begin{array}{l}\text { Male } \\
\text { Visiting }\end{array}$ & 1.462 & {$[1.1602 .017]$} & 0.021 \\
$\begin{array}{l}\text { a dental } \\
\text { practitioner }\end{array}$ & & & \\
No & 1 & & \\
Yes & 0.362 & {$[0.251 ;$} & 0.001 \\
$\begin{array}{l}\text { Use of } \\
\text { toothpicks }\end{array}$ & & $0.516]$ & \\
Yes & & & \\
No & 1 & & \\
\hline
\end{tabular}

Abbreviations: OR: Odd Ratio; CI: Confidence Interval
Treatment needs of the School Aged Children at Kimironko II Primary School.

Among all the participants, majority of them, $383(58.0 \%)$, needed preventive treatments whereas $236(35.8 \%)$ were in need of early dental care within several weeks and $40(6.1 \%)$ in need of immediate referral for pain or infection that required immediate treatment. (Table 4).

Table 4. Treatment needs of the participants(n=660)

\section{Variables Frequency Percentage}

Oral health

(n) (\%)

education,

fissure sealant

383

58

and fluoride

application

Dental scaling

and filling)

236

Extraction

and drainage

of dental ab-

40

scess

In need of

immediate

referral for

other medical

condition

Total

660

100

\section{Discussion}

In this study, dental caries prevalence among school aged children was found to be $42.42 \%$. This prevalence of dental caries in school aged children is still low compared to what many other studies found in middle income and developed countries like USA (50.5\%), India (49\%), Jordan (78.7\%), Saudi Arabia (80\%), and Pakistan (60\%).[14-16] The observed difference in prevalence could be due to the fact that children in developed countries are more exposed to sugary food consumption compared to African children.[17] Relative to other African countries, the prevalence in this study is still lower compared to Nigeria (98.6\%), Tanzania (61\%), Uganda (47\%) and Mozambique $(45 \%) \cdot[15,18]$ This difference could be attributed to the fact that in Rwanda there is no frequent taking of sugary drinks and food consumption compared to some other African countries. As an example in Madagascar, one out of four pupils reported daily consumption of sweets which is one of the factors contributing to the development of dental caries.[19] 
In this present study, gender was statistically significantly associated with dental caries in school children where males were 1.4 times more likely to develop dental caries compared to females (OR:1.462;95\%CI:1.160-2.017; $\mathrm{p}=0.021$ ). This finding is consistent with what was found in the study done Nigeria where more males had dental caries than female; and the explanation was that the females paid more attention to their appearance and oral health than males.[20] Likewise, in India, another study reported gender to be statistically significantly associated with dental caries where a higher prevalence was found in boys than girls(47.3\%) and this difference was related to poor knowledge and awareness towards oral health practices among the boys.[21]

Visiting a dental practitioner reduced the chance of developing dental caries compared to not doing so (OR: 0.362, 95\%CI: 0.251-0.516; $\mathrm{p}=0.001$ ). Similar finding were reported in Bahir Dar City (India),[22]. Conversely, in Hong Kong, children with previous irregular dental visits had a higher chance of developing dental caries compared to those who had regularly done so.[23]

In this study the non-use of toothpicks increased the likelihood of developing dental caries twice as much as its use (OR:2.149; 95\% CI:1.251$4.395 ; p=0.036)$. These findings are similar to those found in different studies which have shown a positive association between use of miswak (chewing sticks from a shrub Salvadora persica) and oral hygiene; there was a positive impact in reduction of dental caries.[24, 25]

Age, sugary drinks consumption, frequency of tooth brushing, dental floss, toothpaste and toothbrush use were not statistical significantly associated with dental caries among children of Kimironko II Primary School. This may be due to the limited use of dental floss and sugary soft drinks by the majority of the Rwandan population.

Given the context, the prevalence of dental caries is high in primary school and it is a public health problem concerning many health institutions and sectors. Therefore, oral health education and other preventive measures like fluoride application, use of sealants, use of fluoridated water or toothpaste should be taken into account to help school aged children mainly by focusing on the risk factors found to be associated with this disease in school aged children.

\section{Conclusion}

The findings of this current study shows that dental caries is highly prevalent among the children of Kimironko II Primary School (42. $42 \%)$. The identified risk factors associated with dental caries are gender, dental visits and use of chew stick or miswaks. Therefore, appropriate preventive measures should be put into action in order to protect that concern school aged children. A good follow up of those with dental caries for treatment need is recommended.

Limitation of the study

The limitation was that researchers used secondary data, which missed some important information such as class level of every pupil. Only the age of the pupil had been recorded.

\section{Acknowledgment}

The authors are thankful the university of Rwanda, College of Medicine and Health sciences through the School of Dentistry the support given to conduct community outreach at Kimironko II Primary School which helped to get these data of the study. JM is a PhD CARTA fellow.

\section{Conflict of interest}

The authors declare no conflict of interest in relation to presentation of this manuscript.

\section{Authors' contribution}

All authors contributed to the design and implementation of the study. They all participated in the development of first draft and approved together the final draft of the manuscript for publication.

This article is published open access under the Creative Commons Attribution-NonCommercial NoDerivatives (CC BYNC-ND4.0). People can copy and redistribute the article only for noncommercial purposes and as long as they give appropriate credit to the authors. They cannot distribute any modified material obtained by remixing, transforming or building upon this article. See https:// creativecommons.org/licenses/by-nc-nd/4.0/ 


\section{References}

1. Ozdemir D. Dental Caries: The Most Common Disease Worldwide and Preventive Strategies. Int J Biol. 2013;5:55-61.

2. Manton DJ. Child Dental Caries - A Global Problem of Inequality. EClinicalMedicine. Elsevier Ltd; 2018;1:3-4.

3. Technical WHO, Note I, Facts KEY. Sugars And Dental Caries. J Public Health Dent. 1944;4:7-7.

4. Fleming E, Afful J. National Center for Health Statistics. National Health and Nutrition Examination Survey (NHANES): 2015-2016. NCHS Data Brief. 2018;1-8.

5. Smadi L, Azab R, Khlaifat F, Rodan R, Abdalmohdi A, Maata R, et al. Prevalence and severity of dental caries in school students aged 6-12 years in Mafraq governorate: Northeast of Jordan. $J$ Oral Heal Oral Epidemiol. 2017;6:40-7.

6. Pratyay Pratim Datta PD. Prevalence of Dental Caries among School Children in Sundarban, India. Epidemiol Open Access. 2013;03.

7. Lalloo R, Hobdell MH, Mosha HJ, Mboli F, Tanda A. Dental caries status of 5-7 year old children in three districts in Tanzania, Uganda and Mozambique. Odontostomatol Trop. 1999;22:46-8.

8. Okunade K. January-March 2018 An Official Publication of The National Postgraduate Medical College of Nigeria. 2018;19-26.

9. Mulu W, Demilie T, Yimer M, Meshesha K, Abera B. Dental caries and associated factors among primary school children in Bahir Dar city: A cross-sectional study. BMC Res Notes. 2014;7:1-7.
10. Hiremath A, Murugaboopathy V, Ankola A V., Hebbal M, Mohandoss S, Pastay P. Prevalence of dental caries among primary school children of India - A cross-sectional study. J Clin Diagnostic Res. 2016;10:ZC4750.

11. Shewade HD, Govindarajan S, Thekkur P, Palanivel C, Muthaiah M, Kumar AM V, et al. Public Health Action. 2016;I:242-6.

12. Janakiram C, Antony B, Joseph J, Ramanarayanan V. Prevalence of dental caries in India among the WHO index age groups: A meta-analysis. $J$ Clin Diagnostic Res. 2018;12:ZE08-ZE13.

13. Singh S. Dental Caries Rates in South Africa: Implications for Oral Health Planning. South African J Epidemiol Infect. 2011;26:259-61.

14. Scaglia P, Niknamdeh A. Assessment of current oral health knowledge attitude and oral hygiene practices among 12-year old school children and patients attending the dental facility at Vezo Hospital in the rural village of Andavadoaka, Madagascar Philipp Scaglia Aryan Niknamdeh. Acad Regia Odontol. 2017;205:1-24.

15. Akinyamoju CA, Dairo DM, Adeoye IA, Akinyamoju AO. Dental caries and oral hygiene status: Survey of schoolchildren in rural communities, Southwest Nigeria. Niger Postgrad Med J. Medknow Publications and Media Pvt. Ltd.; 2018;25:239.

16. Chen KJ, Gao SS, Duangthip D, Li SKY, Lo $\mathrm{ECM}$, Chu $\mathrm{CH}$. Dental caries status and its associated factors among 5-year-old Hong Kong children: A cross-sectional study. BMC Oral Health. BMC Oral Health; 2017;17:1-9.

17. Halawany HS. A review on miswak (Salvadora persica) and its effect on various aspects of oral health. Saudi Dent J. King Saud University; 2012;24:63-9.

18. A. Togoo R, Yaseen S, Zakirulla M, V S N, Al Zamzami M. Oral hygiene knowledge and practices among school children in a rural area of southern Saudi Arabia. Int J Contemp Dent. 2012;3:57-62. 